\title{
Nuchal Translucency in Normal Fetus and Its Variation With Increasing Crown Rump Length (Crl) and Gestational Age
} Karki S, ${ }^{1}$ Joshi KS, ${ }^{1}$ Tamrakar SR, ${ }^{2}$ Regmi S, ${ }^{1}$ Khanal K ${ }^{3}$

\author{
${ }^{1}$ Department of Radiodiagnosis and Imaging \\ ${ }^{2}$ Department of Obstetrics and Gynecology \\ ${ }^{3}$ Department of Community Medicine
}

Dhulikhel Hospital - Kathmandu University Hospital Kathmandu University School of Medical Sciences Dhulikhel, Kavre, Nepal

\section{Corresponding Author}

Subindra Karki

Department of Radiodiagnosis and Imaging

Dhulikhel Hospital - Kathmandu University Hospital Kathmandu University School of Medical Sciences Dhulikhel, Kavre, Nepal

Email: subindra1137@hotmail.com

\section{Citation}

Karki S, Joshi KS, Tamrakar SR, Regmi S, Khanal K. Nuchal Translucency in Normal Fetus and Its Variation With Increasing Crown Rump Length (Crl) and Gestational Age. Kathmandu Univ Med J 2013;44(4):282-286.

\section{ABSTRACT}

\section{Background}

Nuchal translucency (NT) is the fluid collection behind the fetal neck which can be measured by ultrasound at 11-14 weeks of gestation. Increase in the nuchal translucency thickness is associated with various congenital anomalies.

\section{Objective}

To study the relationship between nuchal translucency thickness, crown rump length and gestational age in normal fetus.

\section{Methods}

Prospective analytical study conducted on 211 pregnant women from March 2011 to August 2012. Measurement of Nuchal translucency thickness and crown rump length was performed by ultrasound at 11-14 weeks of gestation. The relationship between nuchal translucency thickness, crown rump length and gestational age was studied by using linear regression analysis.

Results

The mean CRL was $63.67 \pm 13.48 \mathrm{~mm}$ (range $41.2-88 \mathrm{~mm}$ ) and mean NT thickness was $1.55 \pm 0.35 \mathrm{~mm}$ (range $0.8-2.7 \mathrm{~mm}$ ), respectively. The median gestational age was 12.9 weeks. The regression equation which shows relation between median NT thickness and CRL was described as follows: expected NT thickness $=0.013 C R L+0.725$, ( R2 = $0.258, p<0.001)$. There was increase in the incidence of NT thickness more than or equal to $2.5 \mathrm{~mm} ; 1.7 \%$ in fetus between $12-12.9$ weeks of gestation to $15.1 \%$ in fetus between 14.0-14.9 weeks.

\section{Conclusion}

Our study offers normative data of NT thickness in normal fetus, which can be used as reference to screen various chromosomal and congenital abnormalities between 1114 weeks of gestation. NT thickness increased with increasing CRL and a false positive rate increases with increasing gestational age.

\section{KEY WORDS}

Crown Rump length, gestational age, nuchal translucency

\section{INTRODUCTION}

Collection of fluid behind the neck of fetus occurs partly because of fetus's tendency to lie on its back and laxity of the skin of the neck. It can be detected as nuchal translucency (NT) by ultrasound scanning. More the fluid that has accumulated, the greater the risk of an abnormality being present. ${ }^{1}$ It can represent the end point of several pathological processes, including heart failure like ankle edema in adult population.
Although the pathophysiologic mechanism leading to a thickened NT in fetuses during first trimester remains undetermined, the association of a thickened NT and fetal aneuploidy has been demonstrated. ${ }^{2}$

NT measurement of $\geq 2.5 \mathrm{~mm}$ between $10^{\text {th }}$ and $13^{\text {th }}$ week of gestation is associated with a higher rate of fetal chromosomal defects. It is particularly important in early detection of Down's syndrome. ${ }^{3}$ 
Even in a chromosomally normal fetus, the appearance of thickened NT during 11-14 weeks of gestation is also strongly associated with fetal structural defects, genetic syndromes, and poor perinatal outcomes. ${ }^{1,4,5}$

Various studies have shown a strong association between cardiac defects and increased NT thickness. ${ }^{6,7,8}$

Therefore it is important to establish normative data for the distribution of NT thickness with increasing crown rump length (CRL) and gestational age. Here we report our results of ultrasound measurement of NT thickness in 211 normal fetuses between 11 and 14 weeks of gestation.

\section{METHODS}

This was a prospective analytical study conducted on 211 patients presenting to Department of Radiodiagnosis and Imaging at Kathmandu University Dhulikhel hospital from March 2011 to August 2012

The study was approved by Kathmandu University School of Medical Sciences Institutional Review Committee. A detailed history was taken. Written informed consent was obtained and proforma was filled up.

The data were collected from pregnant women with singleton pregnancies in whom fetal ultrasound was performed and the fetal NT thickness was measured between 11 and 14 weeks of gestation (CRL: 40-88mm)

Pregnancy outcomes were reviewed from the obstetric and neonatal records. Only cases with a known normal outcome were included. The excluded cases were those with no obstetrical or neonatal records, cases affected by chromosomal and major structural abnormalities and those resulting in miscarriage or intrauterine death.

The gestational age was calculated from the first day of the last menstrual period and was confirmed by measuring crown-rump length. If discrepancy of more than seven days was observed between estimated gestational age by menstrual period and ultrasound, the ultrasound value was used.

Sonographic evaluation of fetal NT thickness was performed transabdominally using $3.5 \mathrm{MHz}$ convex transducer in Siemens acusion $x-150$ and x-300(CA 94093 USA) USG machine. The fetus which was in a good mid-sagittal section occupied at least $75 \%$ of the image on the screen. (Fig 1)

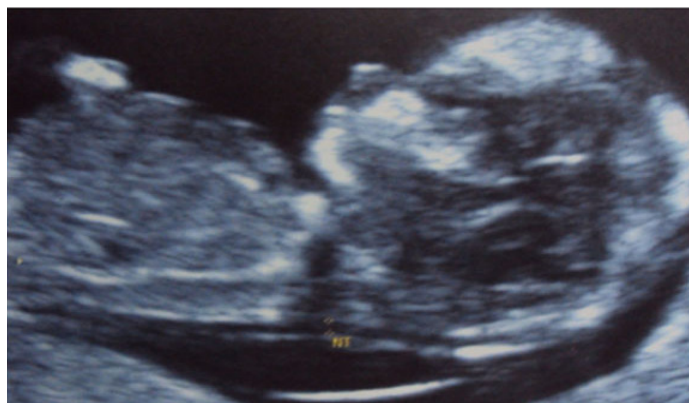

Figure 1. Nuchal Translucency (NT) Thickness Measurement Taken on Transabdominal Ultrasound.
The NT was defined as the black area between the inner skins outlines echo and the outer border of the soft tissue overlying the cervical spine. The intersection of the two arms of the calipers were placed on the outer border of cervical spine and inner border of the skin lying directly posterior to it respectively, to produce a measurement of the transonic or echo-poor nuchal fluid only (Fig. 1). This procedure was repeated twice or more, each from a different image. The largest of the three measurements was taken to evaluate the adjusted risk. The fetal crown-rump length (CRL) was measured simultaneously. Overextension of fetal neck was avoided since it can cause false increase in measurement. ${ }^{9}$

Care was taken to distinguish between the fetal skin and the amniotic membrane. In some cases when it was difficult to measure nuchal translucency due to fetal position, we had to wait for spontaneous fetal movement away from the amniotic membrane or ask the mother to have a brisk walk. As the fetal movement was rapid and short lived, the cine-loop facility was employed to capture the optimal section. In order to minimize operator dependent error, the measurements were reconfirmed by another radiologist.

Statistical analysis was done by using SPSS software version 16.0. The linear regression method was analyzed to establish the correlation between fetal NT and CRL. According to the regression equation, the expected $5^{\text {th }}$, $50^{\text {th }}$, and $95^{\text {th }}$ percentile values of NT were obtained for a given CRL. The cases were subdivided into five groups by the CRL of the fetuses with $10-\mathrm{mm}$ intervals. The median value of NT thickness in each CRL category was calculated to correct for the gestational effect.

\section{RESULTS}

A total of 211 pregnancies from March 2011 to August 2012 satisfied the above inclusion criteria and were enrolled in our study. The mean maternal age was $25.03 \pm 4.92 \mathrm{yrs}$ (range 17-44 yrs). The mean CRL was $63.67 \pm 13.48 \mathrm{~mm}$ (range 41.2-88 mm), mean NT thickness was $1.55 \pm 0.35 \mathrm{~mm}$ (range 0.8-2.7 mm), respectively. The median gestational age was 12.9 weeks.

The distribution of NT thickness in relation to CRL according to simple linear regression is shown in fig 2. NT thickness increased with CRL estimates of gestational age.

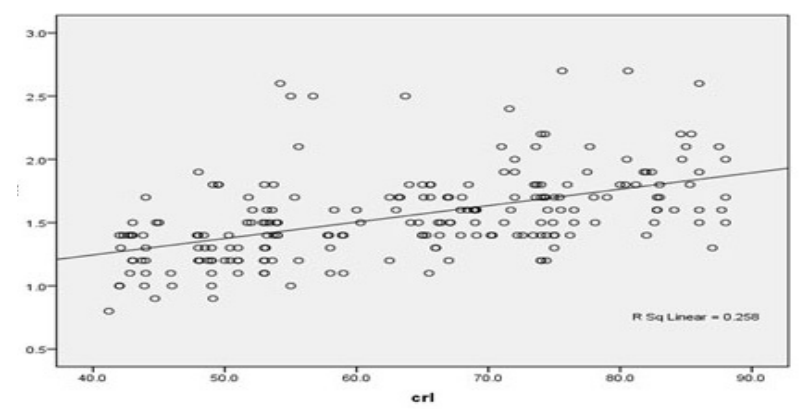

Figure 2. Distribution of Nuchal Translucency (NT) Thickness in Normal Fetus with Crown Rump Length (CRL). 
The regression equation which shows relation between median NT thickness and CRL was described as follows: expected NT thickness $=0.013 C R L+0.725,(R 2=0.258, p$ $<0.001)$.

Table 1 has listed the expected $5^{\text {th }}, 50^{\text {th }}$ and $95^{\text {th }}$ percentile values of NT thickness to CRL. There is increase in median NT thickness from $1.2 \mathrm{~mm}$ when CRL was $40 \mathrm{~mm}$ to $1.9 \mathrm{~mm}$ with CRL measuring $85 \mathrm{~mm}$.

Table 1. Expected 5th, 50th, and 95th percentile values of NT thickness to CRL.

\begin{tabular}{|cccc|}
\hline CRL (mm) & 5th percentile & 50th percentile & 95th percentile \\
\hline 40 & 0.8 & 1.2 & 1.67 \\
\hline 45 & 0.86 & 1.29 & 1.89 \\
\hline 50 & 0.93 & 1.35 & 2.04 \\
\hline 55 & 1.0 & 1.42 & 2.12 \\
\hline 60 & 1.06 & 1.49 & 2.2 \\
\hline 65 & 1.13 & 1.57 & 2.3 \\
\hline 70 & 1.19 & 1.64 & 2.42 \\
\hline 75 & 1.25 & 1.72 & 2.5 \\
\hline 80 & 1.32 & 1.81 & 2.6 \\
\hline 85 & 1.4 & 1.9 & 2.7 \\
\hline
\end{tabular}

The distribution of NT thickness with $10 \mathrm{~mm}$ interval of CRL is shown in table 2 .

Table 2. Results of the Five Categories Based on Crown-Rump Length (CRL) in 10-mm Intervals.

\begin{tabular}{|lllll|}
$\begin{array}{l}\text { CRL } \\
\text { (MM) }\end{array}$ & Number & Percentage & $\begin{array}{l}\text { Mean-SD } \\
\text { NT(MM) }\end{array}$ & $\begin{array}{l}\text { Median } \\
\text { NT(MM) }\end{array}$ \\
\hline $40-49$ & 41 & 19.4 & $1.26+0.23$ & 1.2 \\
\hline $50-59$ & 49 & 23.2 & $1.48+0.36$ & 1.4 \\
\hline $60-69$ & 42 & 19.9 & $1.57+0.23$ & 1.6 \\
\hline $70-79$ & 48 & 22.7 & $1.67+0.32$ & 1.7 \\
\hline$>80$ & 31 & 14.7 & $1.83+0.31$ & 1.8 \\
\hline TOTAL & 211 & 100 & $1.55+0.35$ & 1.5 \\
\hline
\end{tabular}

Table 3 has shown the distribution of NT thickness with gestational age. There was increase in the incidence of NT thickness more than or equal to $2.5 \mathrm{~mm} ; 1.7 \%$ in fetus between $12-12.9$ weeks of gestation to $15.1 \%$ in fetus between 14.0-14.9 weeks. Out of 211 fetus, 9 (4.2\%) fetus had NT thickness greater than or equal to $2.5 \mathrm{~mm}$.

Table 3. Distribution of NT Thickness with Gestation Age.

\begin{tabular}{|lllll|}
$\begin{array}{l}\text { GESTATIONAL } \\
\text { AGE(weeks) }\end{array}$ & $\begin{array}{l}\text { TOTAL NUM- } \\
\text { BER }\end{array}$ & $\%$ & $\begin{array}{l}\text { NT } \geq 2.5 M M \\
\text { NUMBER }\end{array}$ & $\%$ \\
\hline $11-11.6$ & 54 & 25.6 & 0 & 0 \\
\hline $12-12.6$ & 58 & 27.5 & 1 & 1.7 \\
\hline $13-13.6$ & 66 & 31.3 & 3 & 4.5 \\
\hline $14-14.6$ & 33 & 15.6 & 5 & 15.1 \\
\hline Total & 211 & 100 & 9 & 4.2 \\
\hline
\end{tabular}

\section{DISCUSSION}

Extensive research in the last 20 years has established that the measurement of fetal NT thickness provides effective and early screening for trisomy 21 and other major aneuploidies. ${ }^{10-13}$ Furthermore, high NT is associated with cardiac defects and a wide range of other fetal malformations and genetic syndromes. ${ }^{14-16}$ Initially, most studies used a fixed cut-off point to define an abnormal NT measurement during 10-13 weeks of gestation for Down syndrome screening. ${ }^{4,17-22}$ A cut-off point of $\geq 2.5 \mathrm{~mm}$ or of $\geq 3 \mathrm{~mm}$ was usually used. However, subsequent reports have demonstrated that the NT thickness was related to gestational age or fetal CRL. ${ }^{1,10,23,24}$ In the present study, we found that NT thickness increases with CRL which is similar to that of previous studies. . $^{124,25}$

Schuchter et al. have used Multiple of median values to express the relationship between NT measurement and gestational age. ${ }^{26}$ This method is similar to that of biochemical markers used in second-trimester Down screening. ${ }^{27}$

According to previous authors, to base the cut-off on a progressive rise, using $95^{\text {th }}$ percentile as the threshold for an abnormal NT thickness is much appropriate, as it is more sensitive and specific indicator for detection of fetal anomalies. ${ }^{28}$

Thus, it is necessary to establish the normal distribution of fetal NT measurement.

There has been extensive research in the past regarding the value of NT thickness in the first trimester. ${ }^{29-31}$ Interpretation of NT measurement on the basis of ethnic difference is still a matter of debate.

Jou et al. suggested that, given the small but statistically significant NT differences, race-specific normative data should be used. ${ }^{32}$

In a study performed in korean population mean NT thickness was found to be $1.62 \mathrm{~mm}$. Similarly, in a study conducted in Taiwanese population, it was $1.7 \mathrm{~mm} .^{32,33}$

This is comparable to our study in Nepalese population. So we also suggest that ethnicity is not significant in interpretation of NT measurement like other authors. ${ }^{34,35}$

Hence, it is acceptable to use a single standard, because screen positive rates in different NT groups are similar. We found that incidence of NT thickness $\geq 2.5 \mathrm{~mm}$ was $4.2 \%$ which is similar to other studies. ${ }^{6,24}$

Scott et al. observed an increase in the incidence of NT thickness greater than or equal to $2.5 \mathrm{~mm}$ in normal fetuses from $1.3 \%$ at CRL $30-39 \mathrm{~mm}$ to $13.2 \%$ at CRL $60-69 \mathrm{~mm}^{24}$

In our study, the incidence of NT thickness greater than or equal to $2.5 \mathrm{~mm}$ in normal fetuses was $1.7 \%$ at $12.0-12.9$ weeks of gestation and increased to $15.1 \%$ at $14.0-14.9$ weeks. 
Therefore, with the increase in gestational age, there is a false positive rate of increase in NT. So, for the purpose of screening of chromosomal abnormalities, each NT measurement should be examined in accordance to the gestational age.

The nasal bone evaluation at 11 to 14 weeks is used as new ultrasound marker which was found to be absent in about $70 \%$ of fetuses with trisomy 21 and in $0.5 \%$ of chromosomally normal fetuses. It was estimated that screening for trisomy 21 by a combination of maternal age, fetal NT thickness, and examination of the nasal bone could increase the detection rate to $85 \%$ whilst decreasing the false-positive rate to one percent. ${ }^{36}$

There is no association between NT measurement and serum levels of free $\beta$-hCG or PAPP-A in euploid fetuses or in those with trisomy 21 . This independence allows the combination of NT screening and biochemical screening, resulting in a more effective method of risk assessment than either method individually. ${ }^{37,38}$ Wald et al. demonstrated that the combination of NT measurement with maternal serum PAPP-A and free $\beta$-hCG, known as the "combined" first-trimester screening test, results in the detection of $85 \%$ of trisomy 21 fetuses at FPR of $5 \%$. $^{39}$

We admit that our study also has some limitations. The first potential limitation is the small sample size. Another limitation of this study was our inability to utilize transvaginal ultrasound which is a more accurate method as compared to transabdominal scan. This was due to hesitancy of majority of patients to undergo transvaginal scan.

\section{REFERENCES}

1. Hyett J, Perdu M, Sharland G, Snijders R, Nicolaides KH. Using fetal nuchal translucency to screen for major congenital cardiac defects at 10-14 weeks of gestation: population based cohort study. $\mathrm{Br} \mathrm{Med} \mathrm{J.}$ 1999;318:81-85.

2. Berger A. Science commentary: what is fetal nuchal translucency? BMJ. 1999; 318: 85

3. Pandya PP, Snijders RJ, Johnson S, Nicolaides KH (1995). Natural history of trisomy 21 fetuses with increased nuchal translucency thickness. Ultrasound Obstet. Gynecol.1995; 5:381-383.

4. Pandya PP, Kondylios A, Hilbert L, Snijders RJ, Nicolaides KH. Chromosomal defects and outcome in 1015 fetuses with increased nuchal translucency. Ultrasound Obstet Gynecol. 1995;5:15-19.

5. Hafner E, Schuchter K, Liebhart E, Philipp K. Results of routine fetal nuchal translucency measurement at weeks 10-13 in 4233 unselected pregnant women. Prenat Diagn. 1998;18:29-34.

6. Pandya PP, Snijders RJM, Johnson SP, Brizot ML, Nicolaides KH. Screening for fetal trisomies by maternal age and fetal nuchal translucency thickness at 1014 weeks of gestation. Br J Obstet Gynaecol. 1995;102: 95762.

7. Snijders RJM, Johnson S, Sebire NJ, Noble PL, Nicolaides KH. Firsttrimester ultrasound screening for chromosomal defects. Ultrasound Obstet Gynecol. 1996;7:2126.

8. Taipale $P$, Hiilesmaa V, Salonen R, Ylostalo P. Increased nuchal translucency as a marker for fetal chromosomal defects. N Engl J Med. 1997;337:16548
In a developing country like ours, where biochemical and chromosomal markers are highly expensive, unavailable or unaffordable, screening of fetal aneuploidy using sonological measurement of fetal NT thickness seems to be more easily available, cost effective and reasonable.

\section{CONCLUSION}

Fetal NT measurement at first trimester helps in detecting different congenital abnormalities like trisomy 21, 18, 13, Turner's syndrome and various other cardiac abnormalities. The present study shows that there is an increase in NT measurement with increase in CRL and a false positive rate increases with increasing gestational age. Thus, NT measurement should be adjusted according to the gestational age for screening of chromosomal abnormalities. The fixed cut-off point through the first trimester is not appropriate and each NT measurement should be examined according to the gestational age. The current study offers normative data of the fetal NT thickness which can be used as reference for screening various chromosomal and congenital abnormalities.

\section{ACKNOWLEDGEMENT}

The authors would like to thank Mr Seshananda Sanjel, Department of community medicine for contribution in statistical analysis.

9. Whitlow BJ, Chatzipapas IK, Economides DL. The effect of fetal neck position on nuchal translucency measurement. Br J Obstet Gynecol 1998; 105: 872-6.

10. Snijders RJ, Noble P, Sebire N, Souka A, Nicolaides KH. Fetal Medicine Foundation First Trimester Screening Group. 1998. UK multicentre project on assessment of risk of trisomy 21 by maternal age and fetal nuchal translucency thickness at 10-14 weeks of gestation. Lancet 352: $343-346$

11. Wald NJ, Rodeck C, Hackshaw AK. SURUSS Research Group. 2003 a. First and second trimester antenatal screening for Down's syndrome: the results of the Serum, Urine and Ultrasound Screening Study (SURUSS). Health Technol Assess 7: 1-88.

12. Nicolaides KH. 2004. Nuchal translucency and other first-trimester sonographic markers of chromosomal abnormalities. Am J Obstet Gynecol. 191: 45-67.

13. Malone FD, Canick JA, Ball RH. First- and Second-Trimester Evaluation of Risk (FASTER) Research Consortium. 2005. First-trimester or second trimester screening, or both, for Down's syndrome. N Engl J Med. 353: 2001-2011.

14. Hyett J, Moscoso G, Papapanagiotou G, Perdu M, Nicolaides K. Abnormalities of the heart and great vessels in chromosomally normal fetuses with increased nuchal translucency thickness at 1013 weeks of gestation. Ultrasound Obstet Gynecol. 1996;7:24550.

15. Souka AP, Snidjers RJM, Novakov A, Soares W, Nicolaides KH. 1998. Defects and syndromes in chromosomally normal fetuses with increased nuchal translucency thickness at 10-14 weeks of gestation. Ultrasound Obstet Gynecol. 11: 391-400. 
16. Souka AP, Von Kaisenberg CS, Hyett JA, Sonek JD, Nicolaides KH. 2005. Increased nuchal translucency with normal karyotype. Am J Obstet Gynecol. 192: 1005-1021.

17. Nicolaides KH, Azar G, Byrne D, Mansur C, Marks K. Fetal nuchal translucency: ultrasound screening for chromosomal defects in first trimester of pregnancy. BMJ. 1992; 304: 867-9.

18. Pandya PP, Brizot ML, Kuhn P, Snijders RJM, Nicolaides KH. First trimester fetal nuchal translucency thickness and risk for trisomies. Obstet Gynecol. 1994; 84: 420-3.

19. Nicolaides KH, Brizot ML, Snijders RJM. Fetal nuchal translucency: ultrasound screening for fetal trisomy in the first trimester of pregnancy. Br J Obstet Gynaecol. 1994; 101: 782-6.

20. Pajkrt E, Mol BW, van Lith JM, Bleker OP, Bilardo CM. Screening for Down's syndrome by fetal nuchal translucency measurement in a high risk population. Ultrasound Obstet Gynecol 1998; 12: 156-62 increased fetal nuchal translucency at 10-14 weeks gestation. Med Genet. 1998; 35: 222-4.

21. Hafner E, Schuchter K, Liebhart E. Results of routine fetal nuchal translucency measurement at weeks $10-13$ in 4233 unselected pregnant women. Prenat Diagn. 1998; 18: 29-34.

22. Pandya PP, Goldberg H, Walton B, Riddle A, Shelley S, Snijders RJM et.al. The implementation of first-trimester scanning at 10-13 weeks' gestation and the measurement of fetal nuchal translucency thickness in two maternity units. Ultrasound Obstet Gynecol. 1995; 5: 20-5.

23. Pajkrt E, Bilardo CM, Van Lith JMM, Mol BWJ, Bleker OP. Nuchal translucency measurement in normal fetuses. Obstet Gynecol. 1995; 86: 994-7.

24. Scott F, Boogert A, Sinosich M, Anderson J. Establishment and application of a normal range for nuchal translucency across the first trimester. Prenat Diagn. 1996; 16: 629-34.

25. Snijders RJ, Noble P, Sebire N, Souka A, Nicolaides KH. UK multicentre project on assessment of risk of trisomy 21 by maternal age and fetal nuchal-translucency thickness at 10-14 weeks of gestation. Lancet 1998; 352: 343-6.

26. Schuchter K, Wald N, Hackshaw AK, Hafner E, Liebhart E. The distribution of nuchal translucency at 10-13 weeks of pregnancy. Prenat Diagn. 1998; 18: 281-6.

27. Wald NJ, Cuckle HS, Densem JW, Nanchahal K, Royston P, Chard T et.al. Maternal serum screening for Down's syndrome in early pregnancy. BrMed J. 1988; 297: 883-7.
28. Snijders RJ, Johnson S, Sebire NJ, Noble PL, Nicolaides KH. First trimester ultrasound screening for chromosomal defects. Ultrasound Obstet Gynecol. 1996; 7: 216-26.

29. Kim MY, Ryu HM, Kim ES, Han HW, Yang JH, Yoo SJ et.al. The value of increased nuchal translucency (NT) for the prediction of abnormal pregnancy outcome. Korean J Perinatol. 1998; 9: 363-74.

30. Lee JY, Choi KH, Park CW, Yun TS, Park CJ, Jang PR et.al. Fetal nuchal translucency measurement for detection of chromosomal abnormalities in the first trimester of high risk pregnancy. Korean $\mathrm{J}$ Obstet Gynecol. 1998; 41: 2739-42.

31. Kim SJ, Kim CM, Min BS, Sohn WS, Kang JB, Jang PR. The efficacy of nuchal translucency with free beta-hCG, PAPP-A as a screening test for detection of chromosomal anomaly in the first trimester of pregnancy. Korean J Obstet Gynecol. 2001; 44: 1091-6.

32. Jou HJ, Wu SC, Li TC, Hsu HC, Tzeng CY, Hsieh FJ. Relationship between fetal nuchal translucency and crown-rump length in an Asian population. Ultrasound Obstet Gynecol. 2001; 17: 111-4.

33. Chung JH, Yang JH, Song MJ, Cho JY, Lee YH, Park SY et.al. The Distribution of Fetal Nuchal Translucency Thickness in Normal Korean Fetuses. J Korean Med Sci. 2004; 19: 32-6 ISSN 1011-8934.

34. Thilaganathan B, Khare M, Williams B, Wathen NC. Influence of ethnic origin on nuchal translucency screening for Down's syndrome. Ultrasound Obstet Gynecol. 1998;12:112-4

35. Chen M, Lam YH, Tang MH, Lee CP, Sin SY, Tang R, et al. The effect of ethnic origin on nuchal translucency at 10- 14 weeks of gestation. Prenat Diagn. 2002;22:576-8.

36. Cicero S, Curcio P, Papageorghiou A, Sonek J, Nicolaides K. Absence of nasal bone in fetuses with trisomy 21 at 11-14 weeks of gestation: an observational study. Lancet. 2001; 358: 1665-7.

37. Brizot ML, Snijders RJ, Bersinger NA. Maternal serum pregnancy associated plasma protein $A$ and fetal nuchal translucency thickness for the prediction of fetal trisomies in early pregnancy. Obstet Gynecol 1994;84:918-922.

38. Brizot ML, Snijders RJ, Butler J. Maternal serum hCG and fetal nuchal translucency thickness for the prediction of fetal trisomies in the first trimester of pregnancy. Br J Obstet Gynaecol. 1995;102:127-132.

39. Wald NJ, Kennard A, Hackshaw A, McGuire A. Antenatal screening for Down's syndrome. J Med Screen. 1997;4:181-246. 